\title{
"Muy deseada y querida esposa mía de mis ojos": formas nominales en las cartas de llamada escritas por emigrantes a las Américas a sus esposas, siglos XVI a XIX
}

"Muy deseada y querida esposa mía de mis ojos": Nominal Forms in the So-Called cartas de llamada Written by Emigrants to the Americas to their Wives, 16 th to 19th Centuries

BetTina KLUGE

Departamento de Traducción y Comunicación especializada

Universidad de Hildesheim

Universitätsplatz 1. D-31141. Hildesheim, Alemania

klugeb@uni-hildesheim.de

Orcid ID 0000-0003-3797-9841

Resumen: Las cartas de llamada son cartas privadas escritas por personas ya emigradas a las Américas, con las cuales los destinatarios procuraban licencia de embarque para emigrar. El interés tanto de historiadores como de filólogos desde la primera edición de Otte, cubriendo el periodo entre 1540 y 1616, no ha parado. Esta contribución examina las formas nominales empleadas a lo largo de los siglos XVI a XIX, en las cartas de esposos a sus conyúges, identificándose cuatro periodos. Mientras que en el primer periodo, el siglo XVI, se notan formas como señora, hermana, mujer e hija, hasta la mitad del siglo xvIII prevalecen esposa e hija más alguna fórmula de afecto como esposa mía y querida de mis ojos. A partir de 1778, aumentan fórmulas parecidas al tratamiento moderno, especialmente querida + nombre propio.

Palabras clave: Formas nominales de tratamiento. Cartas de Ilamada. Fórmulas de afecto. Emigrantes a las Américas. América española.
Abstract: The so-called cartas de llamada, private letters from persons who already emigrated to the Americas, were presented to the authorities by applicants who also wished to make the dangerous journey. Since the publication of the first edition by Otte (and a later edition along philological criteria by Fernández Alcaide 2009), the interest of historians and linguists has increased enormously. This contribution traces the use of nominal forms of address from the 16th to 19th century in letters written by husbands to their wives in four periods. In the first period, the 16th century, forms such as hermana, mujer and hija were used, while the second period until 1777 is dominated by esposa and hija, plus some additional term of endearment, e.g. esposa mía y querida de mis ojos. In the third and fourth periods, terms similar to the modern nominal address are more numerous, especially querida + first name and querida esposa.

Keywords: Nominal Forms of Address. Cartas de llamada. Terms of Endearment. Emigrants to the Americas. Hispanic America. 


\section{Mi mui estimada esposa y señora de todo mi apresio: [...] \\ Blm tu mui amante esposo que con ansias berdaderas anela por berte, $7 \mathrm{~N}$ \\ Carta 46 (José Nogales a su esposa Rosa Nogales y Reynal, 14.5.1788) [corpus Stangl 2012b, 50]}

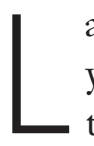
as cartas de llamada son cartas privadas escritas por personas, en su mayoría hombres, ya emigradas a las Américas, mediante las cuales los destinatarios procuraban licencia de embarque para emigrar. Una importantísima colección de ellas se almacena en el Archivo General de Indias (AGI) de Sevilla. Desde la primera edición de Otte (1988) (ver también la versión editada conforme a criterios filológicos por parte de Fernández Alcaide), el interés tanto de historiadores como de filólogos no ha parado. Mientras Otte y Fernández cubren el periodo entre 1540 y 1616, otras publicaciones se enfocan en épocas posteriores (ver el estado de la cuestión de García Hidalgo, aunque se pone más énfasis en los estudios historiográficos; para un panorama desde la lingüística, ver Usunáriz 2012).

Respecto a las formas de tratamiento empleadas en estas cartas, Bentivoglio analiza las formas pronominales (vos, vuestra merced y ella) en un subcorpus de treinta y una cartas del siglo XVI, dirigidas por esposos emigrados a Indias a sus mujeres en Andalucía, mediante las cuales trataban de convencerlas de emprender el peligroso viaje al Nuevo Mundo. Bentivoglio nota poca variación en el tratamiento nominal, aparte de las diferentes grafías para señora. Sin embargo, al ampliar el panorama a cartas escritas en siglos posteriores (ver Macías/Morales; Stangl 2012a; 2012b), se perciben importantes cambios en las formas nominales de tratamiento, reflejándose los cambios en la relación social entre los cónyuges a lo largo de los siglos. Además, como se discute en Stangl (2012a), no hay que olvidar que las cartas almacenadas en el AGI fueron escritas más y más a menudo con la intención de ser presentadas ante las autoridades para obtener licencia de embarque.

Tras un breve recorrido histórico, esta contribuición examina las formas nominales empleadas a lo largo de los siglos XVI a XIX, en las cartas de esposos a sus cónyuges. Mientras en el siglo XVI la forma dominante es señora, más hermana, mujer e bija, hasta la mitad del siglo XVIII prevalecen esposa e bija, más alguna fórmula de afecto como esposa mía y querida de mis ojos. A partir de 1787, 
aumentan las fórmulas parecidas al tratamiento moderno, especialmente querida + nombre propio, además de querida esposa. El uso de modificadores como querida, deseada, estimada, con un alto grado de convencionalismos, posiblemente refleja cambios sociales en cuanto a la propensión de mostrar afecto, o tal vez la adopción de un modelo literario ya en vigor en el Siglo de Oro, como demuestra Hamad con respecto a obras de teatro del siglo XVI.

\section{LAS CARTAS DE LLAMADA EN SU CONTEXTO HISTÓRICO}

Las cartas de llamada incluyen, de alguna u otra forma, los actos de habla de PREGUNTAR/SUPLICAR/SOLICITAR/PEDIR/ORDENAR que alguien, en nuestro caso la esposa, cruce el Atlántico y se reúna con su esposo, quien ya ha pasado algún tiempo en la América española. Es importante darse cuenta de que las cartas formaron parte de un proceso administrativo de emigración, el de pedir licencia de embarque. La carta era presentada ante el Real Consejo de Indias (Toledo, más tarde Madrid) y después ante la Casa de Contratación en Sevilla, con la finalidad de obtener el permiso para emigrar (según Stangl 2012a, 100, las esposas podían acudir directamente a la Casa de Contratación). En el AGI, cada caso archivado contiene al menos dos documentos: la petición (una carta solicitando el tránsito de la persona $\mathrm{X}$ a la América española) y la real cédula ya sea concediendo la licencia de embarque, o arguyendo las razones por las cuales la solicitud fue denegada. Esta práctica fue llevada a cabo durante aproximadamente toda la época colonial, únicamente siendo reemplazada la real cédula, que anteriormente incluso era escrita a mano, por un formulario en 1787.

Otros documentos requeridos por las autoridades incluían el acta bautismal (fe de bautismo) y el testimonio escrito de tres personas para certificar la limpieza de sangre y que no se es hereje (luterano, judío o musulmán). Las personas casadas tenían que presentar su acta matrimonial (fe de casado) y, en el caso de esposos que viajan a las Américas sin sus esposas, también un consentimiento escrito por estas últimas, permitiendo a sus maridos adelantarse en el camino. Se entendía que este consentimiento era por un tiempo limitado: las Leyes de Indias de 1544 especificaban que la reunión de los cónyuges tendría que producirse, en un lado del océano o en el otro, dentro de dos o tres años, aunque se concedía la posibilidad de una prórroga. Según Stangl (2013, 709),

Algunas mujeres se negaron a ir, otras simplemente ya no escucharon más de sus maridos y tenían que emplear personas de confianza para averiguar la residencia de los esposos. Con el material probatorio podían acudir al 
obispo de Cádiz (en el siglo XVIII; antes habrá sido el arzobispo de Sevilla, supongo) para reclamar la vuelta de sus maridos con una "requisitoria".

El riesgo de ser devuelto a España antes de poder amasar una gran fortuna lo sentían muchos esposos, quienes en ocasiones intentaban ocultar su estado civil de casados en la sociedad colonial.

Sumando a lo expuesto anteriormente, las cartas de llamada se empleaban como prueba de que alguien podría ser valioso para la sociedad colonial y no una carga (algunas solicitudes para emigrar fueron denegadas), lo que implica que la selección de la carta correcta para ser presentada ante las autoridades era un acto deliberado, sobre todo en los siglos posteriores al XVI, con el aumento de la comunicación entre los dos continentes. La carta de llamada es de una naturaleza inherentemente políloga, al tener más de un destinatario además del destinatario original. Stangl, citando al historiador Luis Navarro García, subraya que las cartas no solo intentaban convencer a una persona de emprender el viaje a las Américas, sino que también intentaban convencer a las autoridades.

Las cartas son en principio documentos privados, pero en este caso ${ }^{1}$ han sido escritas, o por lo menos utilizadas, con una finalidad pública, la de obtener de las autoridades correspondientes la necesaria licencia para que otros emigrantes acudan a reunirse con sus parientes en Cuba. Por eso, la mayoría de estos documentos abundan en detalles familiares, bien para dar verosimilitud a la oferta que se hace desde la isla, o bien porque se aprovecha una sola misiva para satisfacer dos propósitos: el de informar a la familia y el de hacer constar la conveniencia de que el pariente reclamado parta para América. (Navarro García, en Stangl 2012a, 98)

En consecuencia, Stangl discute el carácter privado de las cartas y propone distinguir entre cartas de llamada y cartas de llamamiento, al menos a partir de la instalación de un sistema de correo más o menos fiable. Antes de ahondar en su argumentación, vale la pena describir el sistema de la flota marítima que conectaba a las Américas y España, para poder entender el impacto que tenía esta organización del flujo de la información en el intercambio de cartas entre personas en las diferentes orillas del Atlántico.

Debido al incremento de la piratería francesa e inglesa, la corona española impuso un sistema de flotas, organizando un conjunto de barcos que viaja-

1. Navarro García dice esto con respecto a la edición de Pérez Murillo de unas cartas de llamada escritas por personas radicadas en Cuba. 
ban al Nuevo Mundo y viceversa. El sistema de la flota funcionó durante gran parte del periodo colonial, a partir de los años 1520 hasta el año 1776. Desde 1564, desde Sevilla y Cádiz, zarpaban dos flotas anualmente, una en abril, la otra en agosto, llegando a las Antillas en conjunto. A la altura de Puerto Rico se dividiría en dos, una hacia Veracruz en el Virreinato de Nueva España, otra hacia Portobelo y Nombre de Dios en Panamá, y Cartagena de Indias en la actual Colombia. Para volver a España, la flota se uniría en La Habana, Cuba. En el siglo XVIII, con la creación del Virreinato de La Plata, también se organizó una flota para Buenos Aires. La flota era precedida por unas naves de aviso que se adelantaban para dar noticia de la llegada de la flota; estas embarcaciones ligeras también llevaban parte del correo (ver Stangl 2012a, 188). En épocas bélicas, para minimizar el riesgo de pérdida de toda la flota, se inició un sistema de registros, naves que cruzaban el océano de forma individual (ver Stangl 2012a, 187). Aparte de ofrecer protección a las naves miembros de la flota, el sistema ayudó a mantener el monopolio comercial español con sus colonias. Se transportaban a América los productos europeos a precios elevados, y volvían de las Indias con el oro y la plata americana, pero también productos naturales como café, cacao, azúcar, algodón y cochinilla. Sin embargo, con la llegada simultánea de tantas mercaderías se dificultó la venta de toda la mercancía. En 1778, con el Reglamento de Libre Comercio para América, se adoptó un sistema de libre comercio entre España y sus colonias, con conexiones entre trece puertos españoles y las Américas, lo que significó el fin del sistema de flotas. Al mismo tiempo se admitió también la emigración desde estos puertos.

En cuanto al transporte de personas y de su correo, desde 1514 fue otorgada a agentes particulares (Correo Mayor) la tarea de la distribución del correo en las Américas. Sin embargo, debido a que el territorio colonial resultaba demasiado grande, el Correo Mayor y sus descendientes solo usaron su privilegio en algunas partes del Perú.

Ante el abandono del correo novohispano, las autoridades imperiales decidieron crear un cargo de Correo Mayor que solo tuviera jurisdicción en Nueva España. A lo largo de dos siglos ambos oficios coexistieron. En el Nuevo Reino de Granada, por su lado, no hubo un cargo de Correo Mayor exclusivo para los márgenes audienciales-virreinales, sino que fueron los principales oficiales locales los que cumplieron tales tareas. (González 39)

Este sistema experimentó un cambio importante en el año 1764, cuando Carlos III instaló un sistema de correo marítimo provisional, que se impuso como 
definitivo mediante la "Real Ordenanza del Correo marítimo" en 1777 (ver Stangl 2012a, 188). Se enviaba un buque de correo cada primer día del mes con destino a La Habana, llevando el correo para el Caribe y Nueva España, y cada dos meses, se hacía una conexión con destino a Buenos Aires, con el correo para los Virreinatos de Río de la Plata y del Perú (ver Stangl 2012a, 188). Adicionalmente, todos los barcos -también de personas particulares- debían llevar una caja postal sellada, que debía de ser entregada intacta en el puerto de destino a las autoridades del puerto. Con tal reforma, las oportunidades de mandar correo se multiplicaron. $\mathrm{Al}$ mismo tiempo, la Corona se aseguró el monopolio de transporte de correo, prohibiendo a las personas privadas el transporte de correos de particulares (ver Stangl 2012a, 188), algo que la Real Cédula de 1514 había permitido explícitamente (el enviar cartas con "familiares" o "criados", ver González 42). Stangl (2012a, 194) calcula que, en los primeros dos siglos de la colonia, una de cada tres cartas menciona a una persona fiable (mensajero, portador) que se hizo cargo de las cartas de familiares, amigos y conocidos.

Sin embargo, el sistema de correo marítimo fue confrontado, desde su inicio, con varios y seguidos conflictos bélicos entre las coronas española y británica. Como subraya Stangl (2012a, 189),

Als offizielle Schiffe, die auch die amtliche Korrespondenz mit sich führten, waren die correos begehrte Beute der Engländer. Bevorzugtes Verhalten der Kapitäne der Schiffe war es, möglichst rechtzeitig die Korrespondenz über Bord zu kippen, um den Engländern keine Informationen in die Hände zu spielen. Besonders 1800 und 1801 waren Jahre fast ohne jede Kommunikation zwischen Spanien und Amerika, was das Auseinanderdriften von Spanien und seinen amerikanischen Besitzungen sicherlich stark beförderte. Mit dem Beginn des spanischen Unabhängigkeitskrieges verkehrten sich die Feindbilder, und beschützt von der englischen Flotte konnte die Seepost vom freien Cádiz aus wieder regelmäßige Verbindungen herstellen. ${ }^{2}$

2. "Como navíos oficiales llevando consigo correspondencia oficial, estos correos eran un botín codiciado por los ingleses. Una de las prácticas preferidas de los capitanes de los barcos era arrojar la correspondencia por la borda antes que facilitársela a los ingleses. Especialmente en los años 1800 y 1801 hubo prácticamente nula comunicación entre España y las Américas, lo que sin duda favoreció fuertemente al alejamiento entre España y sus colonias americanas. Con el inicio de la guerra de independencia española, se invirtieron las imágenes del enemigo y, custodiados por la flota inglesa, el correo marítimo pudo establecer nuevamente una relación continua desde la Cádiz libre”. Agradezco a Liliana Camacho González la corrección idiomática del artículo y la traducción de los ejemplos. 
Por miedo a naufragios y a que se perdiera el correo, se originó la práctica de enviar múltiples copias en diferentes barcos (ver Stangl 2012a, 194), como se menciona en las cartas mismas, citadas en la obra del historiador austriaco. También es frecuente la mención de las fechas de cartas anteriores (ver Stangl 2012a, 223), y en algunos casos se reenviaban las cartas con una nueva fecha (ver Stangl 2012a, 194). De forma periódica, las autoridades coloniales quemaban cartas cuyo destinatario no había sido ubicado - práctica que también disminuyó el material a disposición para el análisis lingüístico-.

En cuanto a las licencias de embarque, antes de 1787 se guardaban tales informaciones en las listas provistas por el Consejo de Indias en las "Informaciones y licencias de Pasajeros a Indias" de las licencias de embarque para toda América entre los años 1534 y 1790. Con la reorganización administrativa, a partir de 1787, las licencias para cada audiencia americana fueron archivadas por separado en las secretarías de las mismas audiencias. Los puertos más importantes para la emigración, según Stangl, eran Cádiz, La Coruña, Gijón, Santander y Barcelona, y en menor grado también Málaga (ver Stangl 2012a, 106-07).

\section{Carta de llamada vs. CARTA DE Llamamiento}

El conocimiento sobre los términos necesarios a emplear para que se obtuviera la anhelada licencia de embarque se difundió rápidamente dentro de las comunidades de personas interesadas en emigrar. Con el paso del tiempo las cartas tendrían una estructura cada vez más prefabricada y breve. También aumenta, durante la época colonial, la práctica de enviar más de una carta: una para ser leída de forma privada y otra para ser presentada ante las autoridades (ver Stangl 2012a, 116). Stangl subraya que los emisores usaban sus palabras de manera cautelosa, ya que "[i]n vielen Briefen finden sich von den Beamten unterstrichene Textpassagen, die jene Teile kennzeichnen, in denen direkt eine Einladung, $\mathrm{Zu}-$ stimmung oder Anwerbung zum Ausdruck gebracht wurde"s (Stangl 2012a, 112).

En consecuencia, las cartas presentadas ante las autoridades llegaron a ser cada vez más cortas y estandarizadas (ver Stangl 2012a, 115). En la práctica administrativa, se comenzó a denominar carta de llamamiento a las cartas cuyo principal objetivo era el de ser presentadas ante las autoridades. Stangl (2012a) cuestiona si las cartas de llamamiento deberían ser vistas como cartas privadas, escritas

3. "En muchas cartas se encuentran pasajes subrayados por las autoridades resaltando las partes donde se expresa directamente una invitación, una aceptación o un reclutamiento". 
por individuos con el fin de contactar a miembros de su familia, o más bien como cartas a la Audiencia, ya que la práctica de enviar dos cartas (una privada y otra oficial) aparentemente era muy común. A veces se puede reconstruir si en esta práctica hubo confusión, como es el caso de Mariano Guillén, quien, en 1793, solicita licencia de embarque mediante la carta privada de su tío, quien menciona en la carta privada que hay otra carta oficial adjunta. No se sabe la motivación del joven, si hubo confusión o si se perdió la carta oficial (ver Stangl 2012a, 116).

Otra señal es la mención cada vez más a menudo del nombre completo de la destinataria o del destinatario, tanto en el saludo como más abajo en la misma carta. Es poco plausible que un emigrado mencione a su sobrino o a su propio hijo mediante el nombre completo. Otro elemento que indica el grado de prefabricación alcanzado a finales del siglo XVIII es el uso de la fórmula digo que en contextos que conducen a una acción oficial, por ejemplo mediante la grafía o un doble punto (ver Stangl 2012a, 118-19). Otras fórmulas son "suplico que" y "comprometo y me obligo" (ver Stangl 2012a, 120). Tales elementos lingüísticos estaban presentes ya en algunas cartas del siglo XVI, pero llegan a ser más frecuentes a partir de 1780 .

\section{EL CORPUS}

Para el presente estudio, se eligieron las cartas escritas por esposos a sus esposas, siempre prestando atención a las clasificaciones hechas por los editores de las colecciones analizadas, ${ }^{4}$ solo del AGI, a diferencia de los datos analizados por Usunáriz $(2012 ; 2015)$.

Se trata de la edición de Marta Fernández Alcaide -una reedición de Otte bajo criterios filológicos- y las ediciones de los historiadores Macías/Morales y Stangl (2012b). Macías/Morales se fijan en las cartas escritas durante el siglo XVIII, como complemento al estudio monumental de Otte. Werner Stangl, historiador austríaco de la Universidad de Graz, intentó encontrar más material del siglo XVII -en su introducción menciona que uno de sus motivos iniciales era, precisamente, la incredulidad con la cual se encontró al leer las publicaciones anteriores-. Sin embargo, él tampoco halló más cartas de llamada de esta época en el AGI, pero sí logró ubicar una cantidad de cartas no editadas anteriormente, sobre todo de finales del siglo XVIII y comienzo del siglo XIX.

4. Hay otras publicaciones más pequeñas, que aquí no tomo en cuenta (pero ver la tabla 1 en Stangl 2013). 
KLUGE. FORMAS NOMINALES EN CARTAS DE LLAMADA DE EMIGRANTES A SUS ESPOSAS

\begin{tabular}{l|c|c|c}
\multicolumn{2}{l|}{ AÑOs Cubiertos } & Total De CARTAS & CARTAS DE ESPOSOS A ESPOSAS \\
\hline Fernández Alcaide & $1540-1616$ & 756 & 102 \\
\hline Macías/Morales & $1700-1799$ & 225 & 160 \\
\hline Stangl 2012b & $1558-1822$ & 1213 & 174 \\
\hline \multicolumn{2}{c}{ Total } & 2194 & 433
\end{tabular}

Tabla 1. Corpus usados, tabulación de las cartas de esposos a esposas.

Como se puede apreciar en el gráfico 1 de Stangl (2012a, 150), carecemos de cartas de llamada entre cónyuges del siglo XVII; no se encuentra ni una carta entre los años 1613 y 1687.

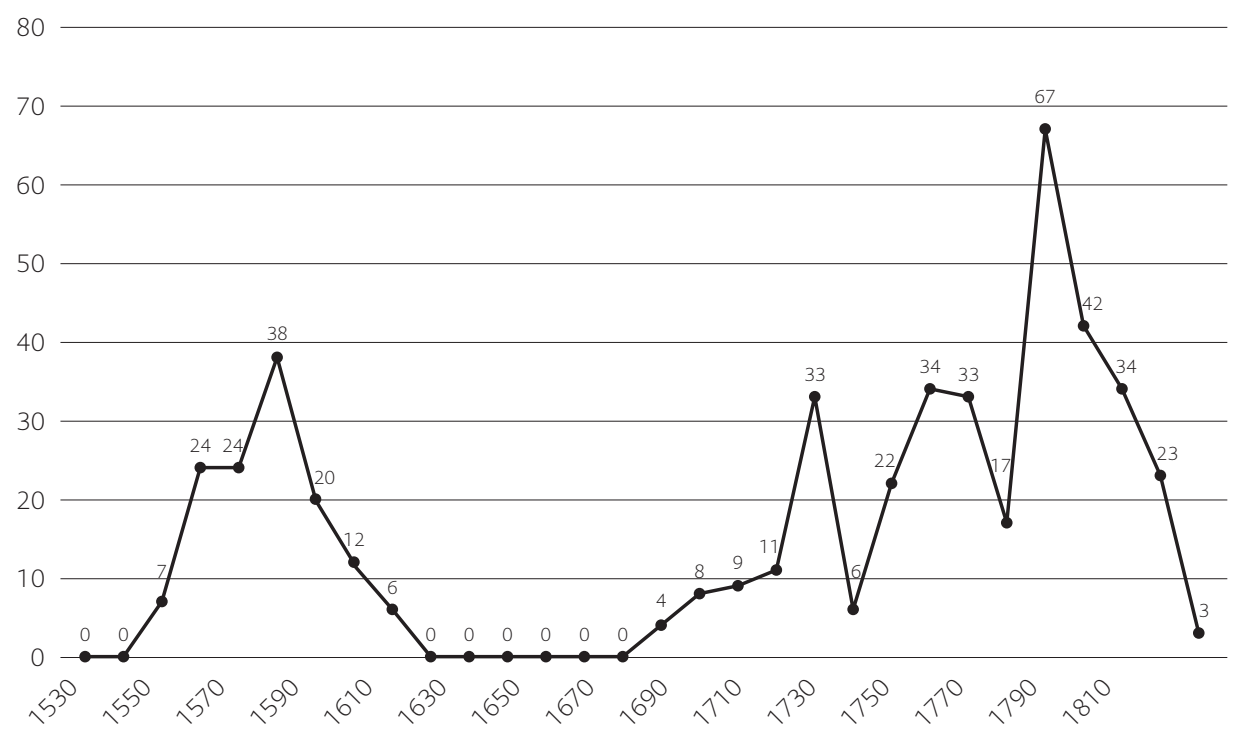

Gráfico 1. Distribución de cartas de llamada por año, subcorpus de cartas escritas por esposos a esposas. Fuente: Stangl (2012a, 150).

No se sabe a qué se debe esa misteriosa discontinuidad de datos en el siglo XVII. Se puede especular que haya habido pérdidas en el Archivo General de Indias. Según el mismo Stangl (2012a, 150), en los periodos de 1560-1600 y 1780-1820, la Real Audiencia también solicitó cartas de llamada/de llamamien- 
to para otras personas (sobrinas y sobrinos, hermanas y hermanos, etc.), ${ }^{5}$ mientras que las esposas tuvieron que presentar estas cartas durante toda la época colonial.

\section{ANÁLISIS DE LAS FORMAS DE TRATAMIENTO NOMINALES}

El siguiente análisis se enfoca en las formas de tratamiento nominal en las 433 cartas de llamada descritas anteriormente, es decir, las cartas presentadas a las autoridades por las esposas de hombres ya emigrados con anterioridad, para conseguir una licencia de embarque y reunirse con sus esposos. Aunque el tratamiento nominal era fuertemente regulado en el discurso público (ver Pragmática de Felipe II, 1586), no lo era así en las relaciones íntimas entre esposo y esposa. Vale recordar que el hecho de tener que escribir a su cónyuge significaba, en la época, una nueva tradición discursiva: había sucedido anteriormente, pero no era común tener que escribir a la esposa, menos aún si esta se encontraba en otro continente. Aparte de ser algo nuevo, obviamente no era algo muy valorado, como se puede apreciar en una fórmula de despedida como tu esposo que más quisiera verte que escribirte, que se observa desde el comienzo de la época colonial -incluso al contener un alto grado de uso formulaico, convencionalizado, y requerido para demostrar a las autoridades que el emisor de la carta sí desea reunirse con su esposa, es una señal de ternura y, a la vez, demuestra que se categoriza la situación como alguna anomalía-.

Por el momento, el análisis se centra en los saludos de las 433 cartas del subcorpus, de los años 1556 hasta 1812. Tal como fue observado en las fórmulas de despedida, se nota un incremento del uso de saludos cada vez más prefabricados en los siglos posteriores. Como veremos en el análisis, es muy aguda la falta de cartas del periodo de 1613 a 1687, con 113 cartas anteriores a 1612 y 323 cartas desde 1688 a 1812 .

Inicialmente, se intentó una división cronológica en dos periodos, de 1540-1612 y de 1690-1812, debido a la falta de cartas de llamada en el siglo XVII. El análisis de los saludos posteriormente hizo necesario que la segun-

5. El periodo de 1780-1820 coincide con la apertura de más puertos de emigración además de Cádiz y la disolución de la Casa de Contratación en 1790. De ahí el intento de la administración colonial de regular el flujo migratorio, conformado sobre todo por varones jóvenes intentando generar su fortuna en el nuevo mundo. 
da fase se dividiera en tres: 1690-1777, 1778-1799 y 1800-1812. Un argumento clave para tal periodización es que a partir del año 1778 incrementó, tras el Reglamento de Libre Comercio, el número de puertos de embarque, facilitando la emigración a personas que vivían en el norte de España y en Cataluña. Aumentó también el número de cartas escritas a personas en estas regiones. (De hecho, hay cartas como la de Esteban Parella, quien escribe a su esposa Teresa Rayna, radicada en Barcelona, en 1791, en una mezcla de catalán y castellano. La saluda "Muy benarade y dueño de mi vide"; obviamente, estimó el castellano como obligatorio para poder entregar la carta a las autoridades; sin embargo, no era el idioma mejor dominado del emisor). La delimitación entre los periodos III y IV no es tan obvia, y no se reflejará tan tajantemente en los datos. Sin embargo, otras razones para considerar los datos del siglo XIX de manera independiente son las siguientes: según Stangl, la situación bélica entre Inglaterra y España había impedido la comunicación transatlántica de tal forma que en los años 1800 y 1801 virtualmente no había correo entre las colonias y España. Es interesante ahora intentar trazar si hay diferencias palpables entre las cartas de los periodos III y IV. Y, de hecho, se puede ver cierta consolidación en los tratos preferidos, como veremos en el apartado 4.4.

En total, el corpus se periodiza de la manera siguiente:

\begin{tabular}{|c|c|c|}
\hline Periodo & AÑOS & NÚMERO DE CARTAS \\
\hline । & 1556-1612 & 113 \\
\hline$\|$ & 1683-1777 & 168 \\
\hline III & 1778-1799 & 108 \\
\hline IV & 1800-1812 & 44 \\
\hline & Total & 433 \\
\hline
\end{tabular}

Tabla 2. Periodización del corpus y número de cartas pertenecientes a cada periodo.

A continuación, he aquí las categorías empleadas para los saludos dentro de los cuatro periodos identificados, antes de analizar cada periodo individualmente. 
Periodo I (1556-1612); $\mathrm{N}=113$

\begin{tabular}{c|c|c|c|c} 
señora & mujer & hermana, hija & $\begin{array}{c}\text { Combinaciones (sobre todo con } \\
\text { señora, hermana, mujer) }\end{array}$ & $\begin{array}{c}\text { Otras, incluyendo } \\
\text { ausencia de saludo }\end{array}$ \\
\hline 54 & 7 & 16 & 15 & 21 \\
\hline
\end{tabular}

Tabla 3. Categorías de forma de tratamiento usado en el saludo en el periodo I.

Periodos II a IV (1683-1812); N = 323

\begin{tabular}{l|c|c|c|c|c} 
& esposa & hija, hermana, prima & $\begin{array}{c}\text { Nombre de pila (NP) } \\
\text { y variaciones }\end{array}$ & Combinaciones & Otros \\
\hline $1683-1777$ & 35 & 35 & 22 & 66 & 10 \\
\hline $1778-1799$ & 52 & 1 & 13 & 40 & 2 \\
\hline $1800-1812$ & 29 & - & 12 & 2 & 1 \\
\hline
\end{tabular}

Tabla 4. Categorías de forma de tratamiento usado en el saludo en los periodos II a IV.

\subsection{Periodo I: análisis del siglo XVI (1556-1612)}

El primer periodo comprende 113 casos; he aquí la tabla.

\begin{tabular}{c|c|c|c|c} 
señora & mujer & hermana, hija & $\begin{array}{c}\text { Combinaciones (con } \\
\text { señora, hermana, mujer) }\end{array}$ & $\begin{array}{c}\text { Otras, incluyendo } \\
\text { ausencia de saludo }\end{array}$ \\
\hline 54 & 7 & 16 & 15 & 21 \\
\hline $\begin{array}{l}\text { señora (21) } \\
\text { señora mía (16) }\end{array}$ & $\begin{array}{l}\text { muy deseada } \\
\text { y querida } \\
\text { mujer(3) }\end{array}$ & $\begin{array}{l}\text { hermana (8) } \\
\text { hija (2) }\end{array}$ & señora hermana (5) & $\begin{array}{l}\text { ausencia de saludo (17) } \\
\text { (sobre todo 1587-1595) }\end{array}$ \\
\hline
\end{tabular}

Tabla 5. Categorías de forma de tratamiento usado en el saludo en el periodo I. 
En este primer tiempo de la época colonial, a causa de la escasez de barcos no se podía escoger entre las cartas que cruzaban el océano. De hecho, en algunos casos las esposas presentaron ante las autoridades cartas que les habían sido escritas en años anteriores; en otros, los esposos se quejaban de no haber recibido respuesta por un tiempo alargado.

Entre los 113 saludos encontrados en este periodo, destaca el uso de $s e-$ ñora, que se encuentra en 54 casos como forma de tratamiento nominal, sea como forma única (21 casos) o en combinación con formas añadidas que incrementan el grado de deseo y ternura. ${ }^{6}$ En dos casos, se combina con el posesivo mi (mi señora) y en 16 casos de manera pospuesta (señora mía). Hay dos mecanismos para aumentar la expresión de ternura: de manera antepuesta, senora se combina con los adjetivos deseada y/o querida, a veces incrementado aún más en combinación con muy o magnífica: deseada señora (2), deseada señora mía (3), muy deseada señora (2), muy deseada señora mia, deseada y querida señora, muy deseada y querida señora, muy [mag] mi señora, muy magca señora. Por otro lado, de manera pospuesta, se añade una frase nominal que resulta ser muy productiva en los siglos posteriores: señora mia de mis ojos (2), señora de mis ojos. La frase nominal de mi(s) $x$ ofrece cierta flexibilidad y se encuentra también en combinación con hermana, hija y mujer: muger mia de my uida, mujer mia de mi [corazon?], br ${ }^{a}$ mia de mis ojos, bija de my alma. Se podría sintentizar de la siguiente forma:

(mi) ((muy) deseada (y querida)) (señora/mujer/hija/hermana) (mía) (de mis ojos/de mi corazón)

Señora se combina además con otras formas de tratamiento base, ya sea unidas mediante el uso de $y$ (señora y hermana) o en combinación directa con otras formas de tratamiento (señora hermana). A causa de la yunción de dos términos que en sí pueden aparecer de forma autónoma, se introdujo en una categoría aparte, en vez de añadirlo a la categoría señora. Mujer, hermana e bija forman dos categorías más dado que tienen cierta importancia en los datos del siglo XVI: señora mujer, señora y muxer, señora muger y hermana, señora hermana (5), muy deseada $s^{a} b r^{a}$ mia, señora y hermana mia, muger y ermana mia. Las combinaciones de señora mujer y señora hermana demuestran el afán de equilibrar la cercanía implicada por hermana con el respeto implicado hacia señora, ya que va li-

6. De aquí en adelante, se usa el lema con la ortografía moderna si es que no se trata de un ejemplo específico tomado de alguna carta. 
gada a una posición superior (al menos metafóricamente, en el ámbito del amor; además, señora es originalmente un título de nobleza). Las únicas combinaciones no documentadas son señora e hija y hermana e hija, hecho muy plausible porque hermana implica no solamente cercanía, sino al mismo tiempo, la pertenencia a la misma generación, lo que no se da en combinación con bija.

La categoría otras, de 21 casos, reúne 17 cartas sin ninguna fórmula de saludo. Además, hay cuatro saludos algo más creativos: alma mia, alma mia y todo mi bien, bien mio, desseada de my coraçón. ' Sin embargo, llama la atención que se usan los mismos mecanismos antes expuestos (posesivo, de mi X).

Prevalecen las formas nominales señora, mujer y hermana, además de las combinaciones formadas a base de estas tres categorizaciones. Las designaciones de hermana e bija para la esposa se deben, posiblemente, al hecho, ya mencionado antes, de que los esposos podían ser devueltos a España si las autoridades estimaban que no había voluntad de vivir junto con la esposa. Como también queda claro en algunas cartas de llamada (ver Stangl 2012a), los esposos trataban de esquivar la censura al dirigirse a sus esposas con otras fórmulas de saludo más inocuas, como bermana o bija: hermana (8), bermana mía (4), br ${ }^{a}$ mia de mis ojos, querida ermana, bija de my alma, bija mía.

El uso de hermana ya fue registrado por Lapesa (21, citado por Bustos 742) en un diálogo entre Sancho Panza y su esposa Teresa en el Quijote. Bustos (746) enumera más ejemplos, inclyuendo uno tomado de la Estoria de Espanna de Alfonso x el Sabio. Según este autor, hermana (y, en menor grado, hermano) no fue un uso muy común y convencionalizado, sino más bien un uso que podría indicar invitación a la reciprocidad, confianza e intimidad. Era más común, al menos en obras literarias, entre personajes de estrato social bajo o marginado (Bustos 747, 751). ${ }^{8}$ En el estudio de Hamad Zahonero (84), quien examina a fondo las formas nominales en un corpus de obras de teatro del siglo XVI, los cuatro casos encontrados en su corpus, enunciados por un solo personaje, corroboran esta interpretación: "Parece que este uso no literal se debe a una forma de solidaridad entre los hablantes, más específicamente una forma de marcar la pertenencia de grupo entre ellos".

7. Para el uso de "señora mía de mi alma" en el estilo cortesano remedado por Cervantes, ver Iglesias Recuero (apartado 3.2) en este mismo volumen.

8. Hermana, en los diálogos literarios clásicos, se comporta como un marcador sociolingüístico del estado plebeyo. No obstante, también las damas cortesanas podían tratarse recíprocamente de bermana, siempre que la interacción no tuviera carácter público. Para la ejemplificación de ambos usos en las novelas ejemplares de Cervantes ver Iglesias Recuero (apartado 3.2) en este mismo volumen. 
Nuestros resultados para el siglo XVI corroboran los de Usunáriz (2012, 557), quien, con base en los datos de 686 cartas entre esposos y prometidos, indica que el saludo entre esposos en el siglo XVI en más del 50 \% comienza por señora " $\mathrm{y}$, en menor medida, por expresiones como muy deseada señora $\mathrm{o}$ hermana". Además de la colección de Otte, Usunáriz recurrió a diferentes fuentes fuera del AGI, entre otros, los fondos del Archivo Diocesano de Pamplona y otros tribunales judiciales (las cartas de prometidos, por ejemplo, servían como prueba en juicios de incumplimiento de promesa matrimonial). También nota unos pocos casos de mujeres escribiendo a sus esposos que aún permanecían en España, y menciona el uso de bijo y hermano.

Con respecto al periodo siguiente, a partir de 1688, es interesante que no encontramos casos ni de esposa ni de prima, y solo dos ejemplos con bija -las formas que dominarán en los siguientes siglos-.

\subsection{Periodo II: siglo XVIII (1688-1777)}

En el segundo periodo, de 1688 a 1777, encontramos 168 casos que se reparten más o menos equitativamente entre las categorías. La comparación con el periodo I demuestra la necesidad de introducir nuevas categorías: mientras senora ha desaparecido por completo, continúan los saludos con bermana e bija, y se le añade una tercera relación de parentesco: prima. Una nueva categoría es esposa, expresión que antes no se encontraba, y una categoría con diferentes combinaciones en torno al uso del nombre de pila. La categoría más importante, sin embargo, es la que combina las denominaciones esposa, bija, hermana o nombre de pila entre sí, más las expresiones de ternura que ya vimos en el primer periodo, cuyo uso va en aumento.

La tabla para el segundo periodo se muestra a continuación:

\begin{tabular}{c|c|c|c|c} 
esposa & hija, hermana, prima & $\begin{array}{l}\text { Nombre de pila } \\
\text { (NP) y variaciones }\end{array}$ & Combinaciones & Otros \\
\hline 35 & 35 & 22 & 66 & 10 \\
\hline $\begin{array}{l}\text { esposa querida (mía) (5) } \\
\text { querida esposa (mía) (7) }\end{array}$ & $\begin{array}{l}\text { hija querida (mía) (6) } \\
\text { hermana (2) } \\
\text { prima (3) }\end{array}$ & $\begin{array}{l}\text { Únicamente NP (4) } \\
\text { mi querida + NP (2) }\end{array}$ & $\begin{array}{l}\text { (esposa/hija) y } \\
\text { querida mía (28) } \\
\text { esposa (21) } \\
\text { hija (9) }\end{array}$ & $\begin{array}{l}\text { Sin saluda (5) } \\
\text { Madata }\end{array}$ \\
\hline
\end{tabular}

Tabla 6. Categorías de forma de tratamiento usado en el saludo en el periodo II. 
Esposa reemplaza a señora en este periodo (o antes, y aquí es muy lamentable la falta de cartas de llamada del siglo XVII). Hija, que antes solo se había utilizado en dos casos, aquí está presente en 30 casos en un periodo algo más largo, con una mayor cantidad de cartas que en el primer periodo. También se encuentran siete combinaciones (sobre todo bija mía) con el nombre de pila y unas 26 combinaciones con otras fórmulas de saludo que podrían utilizarse autónomamente. Aparte de bija querida y esposa, destaca el tipo bija (de mi x) y querida $\mathrm{o}$, alternativamente, bija y querida (de mi X): bija de mi corazón y querida, bija y muy querida mía (4), bija y querida de mi corazón (2), bija y querida de mis ojos (2), bija y querida mía (9), bija y querida mía de mi corazón (4), bija y querida mía de mis ojos. Si bien bija podría ser indicador de una notable diferencia de edad entre los cónyuges, hay que dar cuenta de los casos de bijo en el corpus de Usunáriz (2012), y clasificarlo más bien como señal de ternura.

El patrón general del periodo I se modifica de la siguiente forma:

(mi) ((muy) deseada (y querida)) (esposa/hija/hermana/prima) (mía) (de (todo) mi (mayor) corazón/estimación)

El término hermana, que antes era muy frecuente, en el segundo periodo solo está representado por dos ejemplos: Ermanita, mi más estimada y hermanita querida de mi corazón. Además, hay tres casos de hermana y querida mía (de mi corazón). Aparentemente, el término ya comenzó a especializarse para referirse únicamente a monjas, mientras que bija continuó (y continúa, hasta el día de hoy) siendo una expresión de cariño, sobre todo en su forma diminutiva (mijita). En los tres casos de prima, nuevamente se puede desprender una señal de ternura hacia una persona de la misma generación, y no hay que descartar la posibilidad de que se trate de primos verdaderos.

La categoría más llamativa y nueva en este periodo, sin embargo, es la tercera columna con casos con el nombre de pila, también en su diminutivo, a menudo en combinación con otras fórmulas de saludo. Aquí se puede desprender una gama del nombre diminutivizado (Pepita, Rosita), el nombre sin diminutivo (Fosefa, Elvira), combinaciones con (mi) querida (Mi querida Brígida) y amada (de mi X) (Amada Brígida de mi corazón) hasta combinaciones más formales como Esposa y querida mía Doña María Nicolasa de León y Toledo. Como vimos al comienzo de esta contribuición, Stangl (2012a) ya notó la tendencia de incluir más y más a menudo el nombre completo, conforme los remitentes comenzaban a escribir cartas de llamamiento, conscientes de que estas iban a ser presentadas ante las autoridades. Por lo tanto, no podemos argumentar ne- 
tamente que se trate de una forma precursora de la forma moderna de Queri$d a+N P$, que solamente aparece después de 1787, salvo el caso aislado de Querida fuana mía, de 1768, en la carta de Joaquín Ugarte a Juana Landero (ver Macías/Morales, carta 204).

En la categoría otros, hay cinco cartas sin ningún saludo, es decir, muchas menos que en el periodo anterior. Muchos casos siguen el patrón ya conocido de (mi) (querida) (alma/prenda/querida) (mía) (de mi x): mi alma, querida mía, querida mía de mi vida y de mi corazón, querida prenda de mis ojos. Nótese que querida cambia de clase en la oración (de adjetivo a sustantivo), en el caso de querida mía. Otro caso aislado en la categoría otros es la fórmula Madamita, empleada por Manuel Antonio de Terán, alcalde mayor de Guachinango (México) a su esposa Josefa Navarro, en 1756 (ver Macías/Morales, carta 35) (ver el trabajo de García-Godoy, apartado 6, en este volumen).

\subsection{Periodo III: $1778-1799$}

En el tercer periodo, como ya notamos antes, la procedencia de los remitentes y sus destinatarios cambia notablemente, sin duda debido a la apertura de más puertos de emigración, también en el norte de España (La Coruña, sobre todo) y el puerto de Barcelona. En cuanto a los saludos, se refuerza la tendencia hacia esposa, como se puede ver claramente en la siguiente tabla.

\begin{tabular}{c|c|c|c|c} 
esposa & hija, hermana, prima & $\begin{array}{l}\text { Nombre de pila (NP) } \\
\text { y variaciones }\end{array}$ & Combinaciones & Otros \\
\hline 52 & 1 & 13 & 40 & 2 \\
\hline $\begin{array}{l}\text { querida esposa (mía) (12) } \\
\text { Mi... (11) }\end{array}$ & $\begin{array}{l}\text { querida NP (6) } \\
\text { (entre ellos 3 veces } \\
\text { a Maripepa, } \\
\text { con saludo religioso) }\end{array}$ & $\begin{array}{l}\text { esposa y querida } \\
\text { mía (14) } \\
\text { (no hija) } \\
\text { Esposa, querida, } \\
\text { señora }\end{array}$ & \\
\hline
\end{tabular}

Tabla 7. Categorías de forma de tratamiento usado en el saludo en el periodo III.

Esposa se consolida como la forma más adecuada para comenzar una carta (teniendo en cuenta que posiblemente se utilice para fines oficiales, o sea, pedir licencia de embarque). La primera columna contiene 52 ejemplos de esposa en combinación con más elementos. En la cuarta columna, con los casos con más de dos tratamientos nominales en combinación, esposa forma ahora parte de 
todos los 39 casos de esta categoría, destacándose las siguientes construcciones: esposa y muy querida mía (7), esposa y querida mía (14), Esposa y querida mía de mi mayor estimación (3). Ya no se encuentran casos de bija o bermana. Y vuelve señora, al menos en la combinación con esposa: esposa y señora mía; mi mui estimada esposa y señora de todo mi apresio; muy señora y esposa mía; querida esposa y mui señora mía, querida y amada esposa y muy señora mía.

El patrón de formación, que antes había sido muy abarcable, ahora se transforma en una variedad de posibles formas:

(mi) (más) (estimada/querida/cara) (y querida/estimada) (esposa/querida/amada) (mía) (de mi corazón/de mis ojos/de todo mi cariño/de mi (mayor/singular) estimación/aprecio) (y cariño)

En la segunda columna, se encuentra solo un ejemplo de bija, término que aparentemente ya no se considera adecuado como saludo inicial -sería interesante averiguar en las cartas mismas si se incluyen como vocativo para expresar ternura, tal vez para emular la inmediatez comunicativa (ver Oesterreicher)-.

La tercera columna, de nombres de pila más combinaciones, queda con menos entradas que en el periodo anterior. Entre los 13 casos, hay 6 que muestran la forma moderna de Querida + nombre (Querida Ana Maria/Manuela/Marí/Maripepa (3)). El hecho de que Querida Maripepa aparezca tres veces se debe a las tres cartas de José de Berra quien escribe a su esposa María Josefa Sánchez, en 1791. Además, estas cartas son notables porque contienen una fórmula religiosa antes del saludo (Soledad te guie; Soledad te guie y te ame. Amén.; San Fran[cis]co de Pavia de guia y te ame. Amen.) (ver Stangl 2012b, cartas $832,833,834)$.

\subsection{Periodo IV: 1800-1812}

En el último periodo aquí rastreado, entre los 44 casos se consolida aún más la tendencia antes notada hacia el uso de esposa y/o el nombre de pila.

\begin{tabular}{c|c|c|c|c} 
esposa & hija, hermana, prima & $\begin{array}{c}\text { Nombre de pila (NP) } \\
\text { y variaciones }\end{array}$ & Combinaciones & Otros \\
\hline 29 & - & 12 & 2 & 1 \\
\hline
\end{tabular}

Tabla 8. Categorías de forma de tratamiento usado en el saludo en el periodo IV. 
Una nueva tendencia es que los saludos ahora se multiplican: no es raro que una misma carta comience con dos o incluso tres saludos, como en los tres ejemplos siguientes:

(1) a. Estimadíssima prenda mía de todo mi corazón: Querida esposa: (carta 801)

b. My más estimada y querida esposa de mi corasón: / Amada esposa / (carta 1137$)$

c. Esposa, siempre esposa, la más estimada de todos los esposos (carta 1072)

Por otro lado, la mayoría de los saludos sigue el patrón relativamente corto de (mi) (querida/estimada) esposa: encontramos seis casos de querida esposa, además de tres casos de estimada esposa, y dos de mi estimada esposa. En combinación con el nombre de pila, que se da en 12 casos, destacan dos ejemplos del patrón moderno: Querida Luisa/María. En siete casos de este periodo, se usa el nombre de pila sin apellido, y hay dos casos con nombre y apellido.

En total, el patrón combinatorio del periodo anterior es modificado de cierta forma:

(mi) (más) (estimada/querida/cara) (y queridalestimada) (esposa) (mía) [de (todo) mi corazón/de mis entranias/de (todo) mi cariño y afecto/de mi (mayor) (estimación/aprecio)] (y cariño)

Más a menudo se usa una expresión con corazón como estimada, querida esposa de mi corazón o muy amada esposa de mi corazón. Finalmente, salta a la vista el uso de superlativos en adjetivos como estimadísima y carísima (Carísima esposa mía; Mi estimadísima esposa: mi querida espoza María Rita Pérez).

\section{CONCLUSIÓN}

En esta contribución, he tratado de trazar el uso de las diferentes formas de tratamiento nominal en los saludos de un corpus de cartas de llamada. Mientras dominaba señora en el primer periodo (1556-1612), con un uso considerable de hermana, bija y mujer, a partir de 1683 iba en aumento, cada vez más, la forma esposa, hasta ser la forma dominante en el cuarto periodo. Hija, muy frecuente en el segundo periodo, no juega un papel importante a partir de 1778, igual que hermana y prima. Comenzando más o menos a mitad del siglo XVIII (ya algo antes del tercer periodo), surge el tratamiento moderno de querida + nombre de pila -aunque hay que subrayar que solo lo identificamos así 
conociendo la dirección del cambio lingüístico-. Las cartas, además, dan testimonio del importante rol de las combinaciones, que, de hecho, aparentan ser más estables que las mismas formas base. Para poner un ejemplo, la forma señora mía del siglo XVI pasa, en el siglo XVIII, a esposa mía (y querida de mis ojos); y para la construcción $x$ querida de mi corazón no importa si $\mathrm{x}$ equivale a hermanita, señora, esposa o incluso el nombre propio. Estas formas muy afectuosas -también con uso abundante de formas diminutivizadas- surgen en el segundo periodo, a diferencia de lo que Hamad pudo observar en su corpus literario de obras de teatro del siglo XVI. ¿Posiblemente se trata, por lo tanto, de una lenta acepción del modelo literario en la correspondencia? Alternativamente, habría que analizar más a fondo el cambio de la concepción social de estar casados en cada una de las épocas: las cartas tienen cada vez más un aspecto romántico.

Quedan tareas pendientes a partir de esta contribuición: aún no sabemos por qué un remitente escogió cierta forma en vez de otra -supuestamente podrían hallarse correlaciones entre los actos de habla en la carta misma y las formas de tratamiento-. Una manera de abordar el problema sería examinar los casos donde disponemos de más de una carta escrita por el mismo remitente.

Además, observamos cómo la necesidad de presentar la carta ante las autoridades conduce, en algunos casos, a la mención del nombre completo en el saludo, algo que probablemente no se da en cartas sin esta finalidad. Sería muy interesante, por lo tanto, una comparación entre las cartas de llamada y un corpus epistolar cuyas cartas carecen del rasgo de la polilogicidad, como es el caso en algunas de las cartas analizadas por Usunáriz (2015), por ejemplo las cartas de prometidos y prometidas utilizados posteriormente en juicios de incumplimiento de promesa matrimonial.

Y la gran incógnita sigue siendo el siglo XVII. Sin datos del periodo 1612 a 1683 , es decir, unos setenta años, parece muy brusco el cambio de señora, hermana, bija a esposa y querida + nombre de pila, aunque para los contemporáneos probablemente no existía. Si en el AGI realmente no hay cartas de llamada de este periodo, habrá que buscar otras fuentes, aunque exista el problema de la comparabilidad. Se ofrecen archivos regionales, tanto en España como las Américas, y también los Prize Papers (ver Rutten/van der Wal). Por lo que queda pendiente la cuestión de Stangl (2012a): ¿Qué sucedió en el siglo XVII? 


\section{OBRAS CITADAS}

Bentivoglio, Paola. "Formas de tratamiento en cartas de la segunda mitad del siglo XVI: una aproximación pragmática". Archivo de Filología Aragonesa 59-60 (2002-2004): 229-48.

Bustos Gisbert, Eugenio. "Tratamientos nominales: hermana en el español áureo". El español a través del tiempo: estudios ofrecidos a Rafael Cano Aguilar. Eds. Araceli López Serena, Antonio Narbona Jiménez y Santiago del Rey Quesada. Sevilla: Universidad, 2016. 741-53.

Fernández Alcaide, Marta. Cartas de particulares en Indias del siglo XVI: edición y estudio discursivo. Madrid: Iberoamericana/Frankfurt am Main: Vervuert, 2009.

García Hidalgo, Palmira. "La emigración española a América en la época moderna: un acercamiento al estado de la cuestión”. Naveg@mérica: revista electrónica editada por la Asociación Española de Americanistas 23 (2019): 1-48. 31 de mayo de 2020. <https://revistas.um.es/navegamerica/article/download/397301/272121/>.

González, Nelson Fernando. "Correos y comunicación escrita en la América colonial: esquemas de distribución de la correspondencia oficial (15141768)". Fabrbuch für Geschichte Lateinamerikas 52 (2015): 37-64.

Hamad Zahonero, Nuur. Mucho de "mi coraçón" y de "mi alma" y de "mis entrañas": tratamientos nominales en las relaciones amorosas en el siglo XVI. 2015. Universidad Complutense de Madrid, tesis doctoral. <https://eprints. ucm.es/39781/1/T37903.pdf>.

Lapesa Melgar, Rafael. "Comentario al capítulo v de la segunda parte del Quijote". Actas del III Coloquio Internacional de la Asociación de Cervantistas. Barcelona: Anthropos/Madrid: Ministerio de Asuntos Exteriores, 1993. 174-90.

Macías, Isabelo, y Francisco Morales Padrón. Cartas desde América 1700-1800. Sevilla: Junta de Andalucía, Consejería de Cultura y Medio Ambiente, 1991.

Oesterreicher, Wulf. "Textos entre inmediatez y distancia comunicativas: el problema de lo hablado en lo escrito en el Siglo de Oro". Historia de la Lengua Española. Ed. Rafael Cano Aguilar. Barcelona: Ariel, 2004. 729-69.

Otte, Enrique. Cartas privadas de emigrantes a Indias 1540-1616. México D.F.: FCE, 1993.

Rutten, Gijsbert, y Marijke J. van der Wal. Letters as Loot: A Sociolinguistic Approach to Seventeenth- and Eighteenth-Century Dutch. Amsterdam: John Benjamins, 2014. 
Stangl, Werner. Zwischen Authentizität und Fiktion: Die private Korrespondenz spanischer Emigranten aus Amerika, 1492-1824. Köln/Weimar/Wien: Böhlau, 2012a.

Stangl, Werner. Zwischen Authentizität und Fiktion: Die private Korrespondenz spanischer Emigranten aus Amerika, 1492-1824 (2012b). Apéndice electrónico a Stangl 2012a. 20 de febrero de 2020. <https://www.oapen.org/search?identifier $=437198>$.

Stangl, Werner. "Un cuarto de siglo con cartas privadas de emigrantes a Indias: prácticas y perspectivas de ediciones de cartas transatlánticas en el Imperio español”. Anuario de Estudios Americanos 70.2 (2013): 703-36.

Usunáriz, Jesús María. "Palabras de amor en el mundo hispánico: emociones y sentimientos en la correspondencia privada del Siglo de Oro". Por seso e por maestría: homenaje a la profesora Carmen Saralegui. Eds. Concepción Martínez Pasamar y Cristina Tabernero Sala. Barañáin: EUNSA, 2012. 555-97.

Usunáriz, Jesús María. "Cartas de amor y cartas de emigrantes como prueba judicial en España (siglos XVI-XVIII)". Hispanic Research fournal 16.4 (2015): 296-310. 


\section{APÉNDICE}

Nótese que las categorías dadas se ilustran con la ortografía de hoy en día, con independencia de que se hayan documentado otras variantes gráficas. Por ejemplo, entre los 21 casos de señora en el periodo I se han contabilizado las variantes senora, oñora y sra. Asimismo, para el cómputo de bija se atiende a formas como $i j a, y g a$, etc. Solo se aportan variantes alejadas del estándar ortográfico actual cuando el corpus arroja un único ejemplo.

Periodo I (1556-1612); N = 113

\begin{tabular}{|c|c|c|c|c|}
\hline señora & mujer & hermana, hija & $\begin{array}{l}\text { Combinaciones (con } \\
\text { señora, hermana, mujer) }\end{array}$ & $\begin{array}{l}\text { Otras, incluyendo } \\
\text { ausencia de saludo }\end{array}$ \\
\hline 54 & 7 & 16 & 15 & 21 \\
\hline $\begin{array}{l}\text { señora }(21) \\
\text { señora mía (16) }\end{array}$ & $\begin{array}{l}\text { muy deseada } \\
\text { y querida } \\
\text { mujer (3) }\end{array}$ & $\begin{array}{l}\text { hermana (8) } \\
\text { hija (2) }\end{array}$ & señora hermana (5) & $\begin{array}{l}\text { ausencia de saludo (17) } \\
\text { (sobre todo 1587-1595) }\end{array}$ \\
\hline $\begin{array}{l}\text { Señora (21) } \\
\text { Mi iseñora (2) } \\
\text { Señora mia (16) } \\
\text { Señora mia de mis } \\
\text { ojos (2) } \\
\text { Señora de mis ojos } \\
\text { Deseada señora (2) } \\
\text { Deseada señora mía } \\
\text { (3) } \\
\text { Muy deseada señora } \\
\text { (2) } \\
\text { Muy deseada señora } \\
\text { mia } \\
\text { Deseada y querida } \\
\text { señora } \\
\text { Muy deseada y } \\
\text { querida señora } \\
\text { muy [mag] mi señora } \\
\text { Muy magca señora }\end{array}$ & $\begin{array}{l}\text { Deseada muger } \\
\text { Muy deseada } \\
\text { mujer } \\
\text { Muy deseada y } \\
\text { querida mujer (3) } \\
\text { Muger mia de my } \\
\text { uida } \\
\text { Mujer mia de mi } \\
\text { [corazon?] }\end{array}$ & $\begin{array}{l}\text { Hermana (8) } \\
\text { Hermana mia (3) } \\
\text { Hra mia de mis ojos } \\
\text { Hramia } \\
\text { Querida ermana } \\
\text { Hija de my alma } \\
\text { Hija mía }\end{array}$ & $\begin{array}{l}\text { Lunbre de mis ojos y } \mathrm{s}^{\mathrm{a}} \text { mia } \\
\text { Muy deseada señora mujer (2) } \\
\text { My senora y mi contento } \\
\text { Señora mujer } \\
\text { Señora y muxer } \\
\text { Señora muger y hermana } \\
\text { Señora hermana (5) } \\
\text { Señora y hermana mia } \\
\text { Muger y ermana mia } \\
\text { Muy deseada } \mathrm{s}^{\mathrm{a}} \mathrm{hr}^{\mathrm{a}} \text { mia }\end{array}$ & $\begin{array}{l}\text { Alma mia } \\
\text { Alma mia y todo mi bien } \\
\text { Bien mio } \\
\text { Desseada de my coraçón } \\
17 \text { sin saludo alguno }\end{array}$ \\
\hline
\end{tabular}

Tabla 9. Categorías de forma de tratamiento usado en el saludo en el periodo I (todos los casos). 
Periodo II (1688-1777); N = 168

\begin{tabular}{|c|c|c|c|c|}
\hline esposa & hija, hermana, prima & $\begin{array}{l}\text { Nombre de pila } \\
\text { (NP) y variaciones }\end{array}$ & Combinaciones & Otros \\
\hline 35 & 35 & 22 & 66 & 10 \\
\hline $\begin{array}{l}\text { esposa querida (mía) (5) } \\
\text { querida esposa (mía) (7) }\end{array}$ & $\begin{array}{l}\text { hija querida (mía) (6) } \\
\text { hermana (2) } \\
\text { prima (3) }\end{array}$ & $\begin{array}{l}\text { Únicamente NP (4) } \\
\text { mi querida + NP (2) }\end{array}$ & $\begin{array}{l}\text { (esposa/hija) y } \\
\text { querida mía (28) } \\
\text { esposa }(21) \\
\text { hija (9) }\end{array}$ & $\begin{array}{l}\text { Sin saludo (5) } \\
\text { Madamita }\end{array}$ \\
\hline $\begin{array}{l}\text { Amada esposa, muy querida y mi } \\
\text { más estimada } \\
\text { Carissima esposa mia (2) } \\
\text { Esposa de mi corazón } \\
\text { Esposa de todo mi corazón (2) } \\
\text { Amada y querida esposa } \\
\text { Esposa mía } \\
\text { Esposa querida (3) } \\
\text { Esposa querida de mi corazón (2) } \\
\text { Esposa querida de mi mayor } \\
\text { estimación (2) } \\
\text { Esposa querida mía (2) } \\
\text { Mi muy amada esposa (2) } \\
\text { Mui amada y querida esposa de } \\
\text { mi corazón (2) } \\
\text { Mui amada y querida esposa mía } \\
\text { Mui hamada espossa de mi } \\
\text { corazón } \\
\text { Querida esposa (4) } \\
\text { Querida esposa de mi corazón (2) } \\
\text { Querida esposa de mi mayor } \\
\text { estimación } \\
\text { Querida esposa mía (3) } \\
\text { Querida esposa, amada prenda } \\
\text { mía } \\
\text { Santa Jertrudis te g[u]íe Querida } \\
\text { esposa de mi coraçón: }\end{array}$ & \begin{tabular}{|l|} 
Ermanita, mi más estimada \\
Hermanita querida de mi \\
corazón \\
Estimadísima hija mía, única \\
y sola \\
Hija, Yga (4) \\
Hija de mi corazón \\
Hija de mis ojos \\
Hija mía (2) \\
Hija mía de mi corazón \\
Hija mía de todo mi corazón \\
Hija mía, salud y gracia \\
Hija querida (3) \\
Hija querida de mi corasón (5) \\
Hija querida de mi corazón y \\
de mi alma \\
Hija querida de mi mayor \\
estimación \\
Hija querida de mi vida \\
Hija querida de mis ojos \\
Hija querida mía (3) \\
Yja querida mía \\
Querida hija de mi corazón \\
Querida hija de mi vida \\
Prima y muy querida mía \\
Prima y querida de mi corazón \\
Prima y querida mía
\end{tabular} & $\begin{array}{l}\text { Elvira } \\
\text { Josefa } \\
\text { Rosita } \\
\text { Pepita } \\
\text { Dear Nanny: } \\
\text { Mi querida Brígida } \\
\text { Mi querida Gertrudis } \\
\text { Manuela querida de mi } \\
\text { corazón } \\
\text { Amada Brígida de mi } \\
\text { corazón } \\
\text { Amada mía Gertrudis } \\
\text { María Trechuelo, guarde } \\
\text { Dios. D[oñ]a Ysavel. Hija } \\
\text { mía: } \\
\text { Esposa querida María } \\
\text { Manuela Herrera } \\
\text { Esposa y querida mía } \\
\text { Doña María Nicolasa de } \\
\text { León y Toledo } \\
\text { Espossa de mi vida } \\
\text { D[oñ]a Viz[en]ta Lorenza } \\
\text { Tocado } \\
\text { Hija mía María del Puerto } \\
\text { Hija y querida esposa } \\
\text { Doña Manuela de Lara } \\
\text { Rosales. Hija de mi alma } \\
\text { Querida Ana María Díaz. } \\
\text { Hija y querida mía } \\
\text { Querida esposa Doña } \\
\text { Isabel María de la Torre. } \\
\text { Estimada dueña de mi } \\
\text { corazón: } \\
\text { Querida esposa María de } \\
\text { Arcos y Tenorio. Hija mía } \\
\text { Querida Juana mía } \\
\text { Querida y muy amada } \\
\text { compañera Francisca de } \\
\text { Cáceres } \\
\text { Señora Doña Josefa de la } \\
\text { Oliva y Ruiz. Muy señora } \\
\text { mía y esposa } \\
\text { Señora María } \\
\text { Rodríg[ue]z. Querida } \\
\text { esposa, hijay querida mía }\end{array}$ & $\begin{array}{l}\text { Pepa hija mía } \\
\text { Pepa y querida mía } \\
\text { Pepa, esposa y amada } \\
\text { mía } \\
\text { Esposa hija querida mía } \\
\text { Esposa querida y mi } \\
\text { mayor estimación } \\
\text { Esposa y mui querida mía } \\
\text { de mi mayor estimación } \\
\text { Esposa y querida mía (2) } \\
\text { Esposa y muy querida } \\
\text { mía } \\
\text { Esposa y querida (2) } \\
\text { Esposa y querida de mi } \\
\text { corazón } \\
\text { Esposa y querida mía(19) } \\
\text { Esposa y querida mía de } \\
\text { mi estimazión } \\
\text { Esposa y querida y de mi } \\
\text { mayor estimación } \\
\text { Esposa, s[eño]ra y mi } \\
\text { consorte } \\
\text { Hermana y querida mía } \\
\text { (2) } \\
\text { Hermana y querida mía } \\
\text { de mi corazón } \\
\text { Hija de mi corazón y } \\
\text { querida } \\
\text { Hija querida y esposa } \\
\text { Hija y muy querida mía } \\
\text { (4) } \\
\text { Hija y querida de mi } \\
\text { corazón (2) } \\
\text { Hija y querida de mis ojos } \\
\text { (2) } \\
\text { Hija y querida mía (9) } \\
\text { Hija y querida mía de mi } \\
\text { corazón (4) } \\
\text { Hija y querida mía de mis } \\
\text { ojos } \\
\text { Mi más estimada esposa } \\
\text { y querida mía } \\
\text { Mi más estimada yja y } \\
\text { dueño mío } \\
\text { Muy querida amante y } \\
\text { esposa mía } \\
\text { Querida de mis entrañas, } \\
\text { amada esposa mía de } \\
\text { mis ojos } \\
\text { Querida parienta yseñora }\end{array}$ & $\begin{array}{l}\text { Sin saludo (5) } \\
\text { Madamita } \\
\text { Mi alma } \\
\text { Querida mía } \\
\text { Querida mía de mi } \\
\text { vida y de mi } \\
\text { corazón } \\
\text { Querida prenda de } \\
\text { mis ojos }\end{array}$ \\
\hline
\end{tabular}

Tabla 10. Categorías de forma de tratamiento usado en el saludo en el periodo II (todos los casos). 
Periodo III (1778-1799), N = 108

\begin{tabular}{|c|c|c|c|c|}
\hline esposa & hija, hermana, prima & $\begin{array}{c}\text { Nombre de pila (NP) } \\
\text { y variaciones }\end{array}$ & Combinaciones & Otros \\
\hline 52 & 1 & 13 & 40 & 2 \\
\hline $\begin{array}{l}\text { querida esposa (mía) (12) } \\
\text { Mí... (11) }\end{array}$ & & $\begin{array}{l}\text { querida NP (6) } \\
\text { (entre ellos } 3 \text { veces } \\
\text { a Maripepa, } \\
\text { con saludo religioso) }\end{array}$ & $\begin{array}{l}\text { esposa y querida } \\
\text { mía (14) } \\
\text { (no hija) } \\
\text { Esposa, querida, } \\
\text { señora }\end{array}$ & \\
\hline $\begin{array}{l}\text { Amada esposa (2) } \\
\text { Amada esposa mía de mi corazón } \\
\text { Carísima esposa de mi } \\
\text { estima[ci]ón } \\
\text { Caríssima esposa } \\
\text { Caríssima esposa mía (2) } \\
\text { Esposa amada } \\
\text { Esposa de mi maior cariño } \\
\text { Esposa mía } \\
\text { Esposa muy querida mía } \\
\text { Estimada esposa } \\
\text { Estimada esposa mía } \\
\text { Estimadísima esposa de mi alma } \\
\text { Mi cara esposa mía } \\
\text { Mi estimada esposa } \\
\text { Mi más estimada esposa (3) } \\
\text { Mi más estimada señora (2) } \\
\text { Mi más estimada y querida } \\
\text { esposa de mi corazón } \\
\text { Mi q[ueri]da esposa de mi singular } \\
\text { aprecio } \\
\text { Mi querida esposa } \\
\text { Mi querida y estimada esposa } \\
\text { Mui s[eño]ra mía de mi mayor } \\
\text { aprecio } \\
\text { Muy estimada y querida esposa } \\
\text { de mi corazón } \\
\text { Muy estimada y querida esposa } \\
\text { de mi mayor estimación } \\
\text { Muy mi estimada esposa } \\
\text { Muy querida y estimada espoça } \\
\text { Querida esposa ( } 9 \text { ) } \\
\text { Querida esposa de mi corazón } \\
\text { Querida esposa de mi corazón y } \\
\text { cariño } \\
\text { Querida esposa de mi mayor } \\
\text { veneración } \\
\text { Querida esposa de todo mi } \\
\text { corazón (2) } \\
\text { Querida esposa mía (3) } \\
\text { Querida mía esposa } \\
\text { Querida y amada esposa } \\
\text { Querida y estimada esposa (3) } \\
\text { Queridísima esposa de mi } \\
\text { corazón }\end{array}$ & Mi estimada hija & $\begin{array}{l}\text { Esposa y querida mía Martina } \\
\text { Bujanda } \\
\text { Mariquita Josefa de mi alma } \\
\text { Mi más estimada y querida } \\
\text { Dolores de mi corazón } \\
\text { Mi más estimada y querida } \\
\text { Mariquita } \\
\text { Mi mui amada Juana de toda } \\
\text { mi alma } \\
\text { Querida Ana María } \\
\text { Querida Manuela } \\
\text { Querida María } \\
\text { San Fran[cis]co de Pavia de guia } \\
\text { y te ame. Amen. Querida } \\
\text { Maripepa } \\
\text { Señora D[oñ]a María Thomasa } \\
\text { de Rualde. Mi mui estimada } \\
\text { querida esposa } \\
\text { Señora Doña Josefa Morales. } \\
\text { Esposa y querida mía } \\
\text { Soledad te guíe y te ame. } \\
\text { Amen. Soledad te guíeQuerida } \\
\text { Maripepa }\end{array}$ & \begin{tabular}{|l} 
Esposa y muy querida \\
mía (8) \\
Esposa y mui querida \\
mía de mi maorr \\
estimasión y cariño \\
Esposa y muy estimada \\
mía \\
Esposa y muy querida \\
mía de mi mayor \\
estimación \\
Esposa y muy querida \\
mía de mi mayor \\
estimación y carino \\
Esposa y querida \\
Esposa y querida de mi \\
corazón \\
Esposa y querida de mi \\
mayor estimación \\
Esposa y querida mía \\
(14) \\
Esposa y querida mía de \\
mi maior aprecio \\
Esposa y querida mía de \\
mi mayor estimación \\
(3) \\
Esposa y s[eño]ra mía \\
Mi mui estimada esposa \\
y señora de todo mi \\
apresio: \\
Muy señora y esposa \\
mía \\
Querida amada y \\
esposa de mi alma \\
Querida esposa y mui \\
s[eño]ra mía \\
Querida y amada \\
esposa y muy señora \\
mía \\
Querida y esposa mía de \\
mi ma[yo]r estima[ció]n
\end{tabular} & $\begin{array}{l}\text { Mi más } \\
\text { querida y } \\
\text { estimada } \\
\text { compañera } \\
\text { Muy } \\
\text { benarade y } \\
\text { dueño de mi } \\
\text { vide }\end{array}$ \\
\hline
\end{tabular}

Tabla 11. Categorías de forma de tratamiento usado en el saludo en el periodo III (todos los casos). 
Periodo IV (1800-1812); $\mathrm{N}=44$

\begin{tabular}{|c|c|c|c|c|}
\hline esposa & hija, hermana, prima & $\begin{array}{c}\text { Nombre de pila (NP) } \\
\text { y variaciones }\end{array}$ & Combinaciones & Otros \\
\hline 29 & - & 12 & 2 & 1 \\
\hline $\begin{array}{l}\text { Amada esposa de mis entranias/ } \\
\text { Prenda amada,/ Pero esposa } \\
\text { amamada } \\
\text { Querida esposa (2) } \\
\text { Amada esposa } \\
\text { Carícima estimada esposa } \\
\text { Carida y estimada esposa } \\
\text { Esposa de mi maior cariño y } \\
\text { afecto } \\
\text { Esposa mía de todo mi corasón } \\
\text { Esposa, siempre esposa, la más } \\
\text { estimada de todos los esposos } \\
\text { Estimada esposa (3) } \\
\text { Estimada, q[ueri]da esposa de mi } \\
\text { corazón } \\
\text { Mi estimada esposa (2) } \\
\text { Mi más estimada espoza:, } \\
\text { espoza, } \\
\text { Mi más estimada esposa:/ } \\
\text { Querida esposa:/ } \\
\text { Mi querida esposa (3) } \\
\text { Mui estimada esposa de mi } \\
\text { corazó: } \\
\text { My más estimada y querida } \\
\text { esposa de mi corasón:/ Amada } \\
\text { esposa,/ } \\
\text { Q[u]erida y estimada esposa de } \\
\text { mi mayor estimasión } \\
\text { Querida esposa (4) } \\
\text { Querida y estimada esposa: } \\
\text { Querida y estimada esposa mía } \\
\text { de mi corazón }\end{array}$ & & $\begin{array}{l}\text { Estimada y querida esposa } \\
\text { mya:, Luysa } \\
\text { Estimadísima esposa Juanita } \\
\text { Margarita Rodón Mataró. } \\
\text { Querida esposa: } \\
\text { Mi estimada Ana } \\
\text { Mi estimada esposa:/ Estimada } \\
\text { Dominga,/ } \\
\text { Mi más amada y querida } \\
\text { esposa:/ Juana } \\
\text { Mi más estimada y q[u]erida } \\
\text { esposa de mi corazón:/ Juana } \\
\text { Mi s[eño]ra D[oñ]a Ant[oni]a } \\
\text { Herrera y Godoy Lima yen[er]o } \\
\text { 12/803 Mi estimadísima } \\
\text { esposa: } \\
\text { Mi querida espoza María Rita } \\
\text { Pérez } \\
\text { Mi siempre adorada Cathalina } \\
\text { Querida Luisa } \\
\text { Querida María }\end{array}$ & $\begin{array}{l}\text { Esposa y muy querida } \\
\text { mía } \\
\text { Esposa y querida mía }\end{array}$ & $\begin{array}{l}\text { Estimadíssima } \\
\text { prenda mía } \\
\text { de todo mi } \\
\text { corazón: } \\
\text { Querida } \\
\text { esposa }\end{array}$ \\
\hline
\end{tabular}

Tabla 12. Categorías de forma de tratamiento usado en el saludo en el periodo IV (todos los casos). 